\title{
Association of ADAM33 gene polymorphisms with COPD in a northeastern Chinese population
} Xinyan Wang ${ }^{\dagger 1}$, Lei Li ${ }^{\dagger 2}$, Jinling Xiao ${ }^{1}$, Chengzhen Jin ${ }^{1}$, Kun Huang ${ }^{1}$, Xiaowen Kang ${ }^{1}$, Xiaomei $\mathrm{Wu}^{* 1}$ and Fuzhen $\mathrm{Lv}^{* 1}$

\begin{abstract}
Address: ${ }^{1}$ Department of Respiratory, the Second Affiliated Hospital of Harbin Medical University, Harbin, 150081, PR China and ${ }^{2}$ Department of Neurology, the Second Affiliated Hospital of Harbin Medical University, Harbin, 150081, PR China

Email: Xinyan Wang - wxylyfll@163.com; Lei Li - lilei75@hotmail.com; Jinling Xiao - xiaojinlingxiao@yahoo.com.cn; Chengzhen Jin - jcz912@hotmail.com; Kun Huang - huangkun515@sina.com; Xiaowen Kang - xiaowen801124@yahoo.com.cn; Xiaomei Wu* - wu.xiaomei@hotmail.com; Fuzhen Lv* - fuzhenlv46@yahoo.cn

* Corresponding authors †Equal contributors
\end{abstract}

Published: 10 December 2009

BMC Medical Genetics 2009, 10:132 doi:10.1186/1471-2350-10-132
Received: 22 April 2009

Accepted: 10 December 2009

This article is available from: http://www.biomedcentral.com/I47/-2350/I0/I32

(c) 2009 Wang et al; licensee BioMed Central Ltd.

This is an Open Access article distributed under the terms of the Creative Commons Attribution License (http://creativecommons.org/licenses/by/2.0), which permits unrestricted use, distribution, and reproduction in any medium, provided the original work is properly cited.

\begin{abstract}
Background: Chronic obstructive pulmonary disease (COPD) is influenced by both environmental and genetic factors. ADAM33 (a disintegrin and metalloproteinase 33 ) has been one of the most exciting candidate genes for asthma since its first association with the disease in Caucasian populations. Recently, ADAM33 was shown to be associated with excessive decline of lung function and COPD. The aim of this study was to evaluate the potential relationship between polymorphisms of ADAM33 and COPD in a Han population in northeastern China.
\end{abstract}

Methods: A total of 312 COPD patients and a control group of 319 healthy volunteers were recruited for this study. Eight polymorphic loci (V4, T+I, T2, TI, S2, SI, Q-I, and F+I) of ADAM33 were selected for genotyping. Genotypes were determined by using the polymerase chain reactionrestriction fragment length polymorphism (PCR-RFLP) method.

Results: Statistically significant differences in the distributions of the T2G, TIG, S2C, and Q-IG alleles between patients and controls were observed $(P<0.00 \mathrm{I}$, odds ratio $(\mathrm{OR})=2.8 \mathrm{I}, 95 \%$ confidence interval $(\mathrm{Cl})=2.19-3.6 \mathrm{I} ; P<0.00 \mathrm{I}, \mathrm{OR}=2.60,95 \% \mathrm{Cl}=2.06-3.30 ; P=0.03, \mathrm{OR}=\mathrm{I} .3 \mathrm{I}$, $95 \% \mathrm{Cl}=1.02-1.69$; and $P<0.00 \mathrm{I}, \mathrm{OR}=1.93,95 \% \mathrm{Cl}=1.50-2.50$, respectively). Haplotype analysis showed that the frequencies of the CGGGGAGC, CGGGGAGT, CGGGCAGC, and CGGGGGGC haplotypes were significantly higher in the case group than in the control group ( $P$ $=0.0002,0.0001,0.0005$, and 0.0074 , respectively). In contrast, the haplotype CGAAGAGC was more common in the control group than in the case group $(P<0.000 \mathrm{I})$.

Conclusion: These preliminary results suggest an association between ADAM33 polymorphisms and COPD in a Chinese Han population.

\section{Background}

Chronic obstructive pulmonary disease (COPD) is a major cause of chronic morbidity and mortality. The
World Health Organization (WHO) listed COPD as the fifth leading cause of death in the world, and it is estimated that COPD will be the third most common cause 
of death globally by 2020 [1]. It is also an increasingly common problem in China. A survey of 20,245 participants in seven regions in China in 2007 indicated that the prevalence of COPD in adults aged $\geq 40$ years was $8.2 \%$. The disease is characterized by airflow limitation and is associated with an abnormal inflammatory response of the lungs in response to noxious particles or gases, especially cigarette smoke [1]. These products lead to emphysema and airway remodeling, which is manifested by squamous and mucous metaplasia of the epithelium, smooth muscle hypertrophy, and airway wall fibrosis. These pathological abnormalities interact synergistically to cause progressive airflow obstruction [2]. Cigarette smoke is by far the most important risk factor for COPD, but there is a wide range in disease severities, irrespective of the number of pack years of smoking. Furthermore, only a minority (10-20\%) of smokers develop clinically significant COPD. This suggests that, aside from smoking, there are underlying genetic factors that play a role in the development and severity of COPD. Based on family studies, the estimated relative risk for genetic susceptibility to COPD is about three [3].

ADAM33, is a member of the ADAM (a disintegrin and metalloprotease) family. ADAM proteins are involved in cell adhesion, cell fusion, cell signaling, and proteolysis $[4,5]$. The latter can be illustrated by the capacity to shed cytokines, growth factors, or their receptors from the cell surface and the remodeling of extracellular matrix components. Garlisi demonstrated that ADAM33 is an active proteinase that is able to cleave $\alpha 2$-macroglobulin [6] and synthetic peptides [7]. The enzymatic activity of ADAM33 can be inhibited by tissue inhibitor of metalloproteinase3 and -4 (TIMP-3 and -4, respectively) as well as several small molecules [7]. This suggests that ADAM33 is involved in pulmonary defenses and tissue remodeling. Chronic respiratory diseases such as COPD and asthma are characterized by airflow obstruction and a chronic, persistent inflammatory process. The inflammatory process is a complex interaction between many cellular mechanisms, inflammatory mediators, and their effects [8]. A crucial pathological feature of COPD is airway inflammation and remodeling. Puxeddu et al. [9] showed that a truncated, soluble form of ADAM33 containing the catalytic domain caused rapid induction of endothelial cell differentiation in vitro and angiogenesis ex vivo and in vivo. Although not as well studied, there is evidence that the vascular area of the airway is significantly increased in COPD and that this increase correlates with the degree of airflow obstruction [10].

Genome-wide screening revealed that chromosome 20p13 was significantly linked to asthma and airway hyperresponsiveness in 460 families with asthma from the UK and the USA. This genomic region contains the gene ADAM33 [11]. Since the first report of an association between ADAM33 polymorphisms and asthma in two Caucasian populations from the UK and the USA, a number of replication studies have been published with differing results [12-15]. The differences in the association results may be due to phenotypic and environmental heterogeneity between cohorts. Additional studies demonstrated that SNPs within the ADAM33 locus are associated with accelerated decline of lung function in the general population and in asthma patients [16,17]. The ADAM33 gene is expressed in airway smooth muscle cells and fibroblasts in the lung [18], suggesting that it is not only important in the development of asthma but also in disease progression, possibly through airway remodeling $[19,20]$. These latter findings suggest a function of ADAM33 related to lung growth and repair in general rather than solely associated with asthma. Recent studies revealed that SNPs within ADAM33 confer susceptibility to COPD in the general population and are associated with airway inflammation in COPD $[21,22]$. The aim of the current study was to determine whether ADAM33 SNPs are associated with COPD in a Chinese Han population.

\section{Methods \\ Population subjects}

COPD patients were recruited from the Second Affiliated Hospital of Harbin Medical University in China. A total of 312 patients with stable COPD who had not been previously treated with theophylline, $\beta 2$-adrenergic receptor agonists, or glucocorticosteroids were recruited for this study. The diagnosis of COPD was established using the following criteria: (1) history of cigarette smoking (a minimum of 10 pack years) in patients who were current smokers at the time of evaluation; (2) no exposure (occupational or otherwise) to other substances known to cause lung disorders; (3) absence of atopy; (4) no history of systemic or other pulmonary disease or congenital and/or acquired systemic immunodeficiency; (5) forced expiratory volume in the first second (FEV1)/forced vital capacity (FVC) $<70 \%$ and FEV1 after inhalation of $200 \mathrm{mg}$ salbutamol $<80 \%$. The control group consisted of 319 unrelated subjects with healthy pulmonary function and no known medical illnesses or family disorders. Control subjects were patients visiting the same hospital for a health check-up or community volunteers. They were matched for age, gender, and smoking history with the case group. The characteristics of the study population are shown in Table 1. Participants were of Han origin and lived in Harbin, which is in northeast China.

Approval from the local regional ethics committee was obtained before initiating the study. COPD patients and 
Table I: Description of the studied population

\begin{tabular}{lll}
\hline Characteristic & CASE & CONTROL \\
\hline Number of patients & 312 & 319 \\
Age (years) & $60.5(7.8)$ & $61.5(8.1)$ \\
Male: Female & $186: 126$ & $192: 127$ \\
Pack years of smoking & $35.46(15.9)$ & $32.54(12.7)$ \\
FEVI (\% predicted) & $52.5(8.6)$ & $91.5(9.6)$ \\
FEVI/FVC (\%) & $47.5(7.6)$ & $90.5(11.6)$ \\
Postbd FEVI (\% predicted) & $58.5(9.6)$ & $93.5(10.5)$ \\
Postbd FEVI/FVC (\%) & $49.2(8.5)$ & $91.5(11.8)$ \\
\hline
\end{tabular}

Data are means and standard deviations (in parentheses)

Pack year: (packs per day) $\times$ (years smoked)

FEVI: forced expiratory volume in first second

FVC: forced vital capacity

Postbd: post bronchodilator

healthy controls were informed of the study protocol and provided written consent. Genomic DNA was extracted using a DNA Extraction Kit (Qiagen, Germany) from peripheral blood that was anticoagulated in ACD (acidcitrate dextrose).

\section{Genotyping by PCR-RFLP}

Eight SNPs were chosen from published ADAM33 SNPs associated with excess decline in FEV1 and/or presence of COPD. Information on the selected SNPs is shown in Table 2. Genotyping was performed by polymerase chain reaction-restriction fragment length polymorphism (PCRRFLP) analysis. The polymorphic region was amplified by PCR using a T-Gradient Thermoblock PCR System (Iometra, Germany) in a $25 \mu \mathrm{l}$ reaction solution containing 0.3 $\mu$ g genomic DNA, $10 \times$ PCR buffer, $0.3 \mathrm{mM} \mathrm{MgCl}_{2}, 0.2$ mM dNTPs, 2 U TaqDNA polymerase (Takara, Japan), and $0.1 \mu \mathrm{mol}$ of each primer (Invitrogen, USA). Genotyping primers are shown in Table 2. PCR products were digested overnight with restriction enzymes (NEB, UK) according to the manufacturer's protocol and analyzed by agarose gel electrophoresis. The restriction enzymes and the length of the digested fragments are shown in Table 3.

\section{Statistical analyses}

Each SNP was tested for deviation from Hardy-Weinberg equilibrium (HWE) using the $\chi^{2}$ statistic with expected frequencies derived from allele frequencies. SNPs were excluded from the analysis if they were out of $\operatorname{HWE}(P<$ 0.05). The allele frequencies for the case group and control group individuals were statistically compared using the $\chi^{2}$ test with SPSS software for Windows (version 14.0; SPSS Inc, Chicago, IL). Haplotype frequencies for multiple sites in phase-unknown cases and controls were estimated using the expectation-maximization method of Haploview 4.1 software http://www.broad.mit.edu/mpg/ haploview/. The relative risk associated with rare alleles was estimated as an odds ratio (OR) with a 95\% confidence interval (CI).

\section{Results \\ Distribution of eight polymorphisms in the case and control groups}

Deviations from Hardy-Weinberg equilibrium were not seen in the COPD or control group for any polymorphisms. The genotype frequencies of the ADAM33 SNPS in the COPD and control groups are shown in Table 4. The genotype and allele frequencies were compared between the two groups. The frequencies of the T2G allele, the T1G allele, and the Q-1G allele were significantly higher in cases than in controls $(P<0.001$, OR $=2.81$, $95 \% \mathrm{CI}=2.19-3.61 ; P<0.001, \mathrm{OR}=2.60,95 \% \mathrm{CI}=2.06-$ $3.30 ; P<0.001$, OR $=1.93,95 \% \mathrm{CI}=1.50-2.50$, respectively). Statistically significant differences in the distribu-

Table 2: Description of the investigated ADAM33 SNPs

\begin{tabular}{|c|c|c|c|c|}
\hline Chromosome Position & Reference SNP ID & SNP Name & Alleles & Primer Sequences \\
\hline 3589161 & 2787094 & V4 & $\mathrm{C} / \mathrm{G}$ & $\begin{array}{l}\text { F: 5'-ACACACAGAATGGGGGAGAG-3' } \\
\text { R: 5'-CCAGAAGCAAAGGTCACACA-3' }\end{array}$ \\
\hline 3590127 & 2280089 & $\mathrm{~T}+\mathrm{I}$ & $\mathrm{A} / \mathrm{G}$ & $\begin{array}{l}\text { F: 5'-CTGAGCCCAGAAACCTGATT-3' } \\
\text { R: 5'-AGAAGGGAAGGGCTCATGC-3' }\end{array}$ \\
\hline 3590205 & 2280090 & $\mathrm{~T} 2$ & $\mathrm{~A} / \mathrm{G}$ & $\begin{array}{l}\text { F: 5'-TTCTCAGGGTCTGGGAGAAA-3' } \\
\text { R: 5'-GCCAACCTCCTGGACTCTTA-3' }\end{array}$ \\
\hline 3590234 & 2280091 & $\mathrm{TI}$ & $\mathrm{A} / \mathrm{G}$ & $\begin{array}{l}\text { F: 5'-ACTCAAGGTGACTGGGTGCT-3' } \\
\text { R: 5'-GAGGGCATGAGGCTCACTTG-3' }\end{array}$ \\
\hline 3591742 & 528557 & $\mathrm{~S} 2$ & $\mathrm{C} / \mathrm{G}$ & $\begin{array}{l}\text { F: 5'-AGAGCTCTGAGGAGGGGAAC-3' } \\
\text { R: 5'-TGTGCAGGCTGAAAGTATGC-3' }\end{array}$ \\
\hline 3591765 & 3918396 & SI & $\mathrm{A} / \mathrm{G}$ & $\begin{array}{l}\text { F: 5'-TGTGCAGGCTGAAAGTATGC-3' } \\
\text { R: 5'-AGAGCTCTGAGGAGGGGAAC-3' }\end{array}$ \\
\hline 3592207 & 612709 & Q-I & $\mathrm{A} / \mathrm{G}$ & $\begin{array}{l}\text { F: 5'-GGATTCAAACGGCAAGGAG-3' } \\
\text { R: 5'-GTTCACCTAGATGGCCAGGA-3' }\end{array}$ \\
\hline 3595085 & 511898 & $\mathrm{~F}+\mathrm{I}$ & $\mathrm{C} / \mathrm{T}$ & $\begin{array}{l}\text { F: 5'-CTGCCACAATGTACAGTTCCA-3' } \\
\text { R: 5'-AAGGACTTCTCAACCCACGA-3' }\end{array}$ \\
\hline
\end{tabular}


Table 3: Restriction enzymes and lengths of digested fragments

\begin{tabular}{llllllllll}
\hline & V4 & T+I & T2 & TI & S2 & SI & Q-I & F+I \\
\hline Enzyme & Pstl & HpyAV & HpyCH4III & Ncol & Fsel & Hinfl & BtsCl & BsmBI \\
Length of digested fragments(bp) & G: & A: & A: & A: & C: & G: & A: & C: \\
& $168+206$ & $284+28$ & $198+112$ & $140+260$ & $148+156$ & $132+172$ & $20+138$ & $208+192$ \\
& C:374 & G:3I2 & G:310 & G:400 & G:304 & A:304 & G:158 & T:400 \\
\hline
\end{tabular}

tions of the three alleles were observed between the two groups. The frequency of the $\mathrm{S} 2 \mathrm{C}$ allele was slightly higher in the case group than in the control group $(P=0.031, \mathrm{OR}$ $=1.31,95 \% \mathrm{CI}=1.02-1.69)$. The details are shown in Table 5.

\section{ADAM33 haplotype analysis}

We constructed the haplotypes of cases and controls. Haplotypes with frequencies $>2 \%$ were selected for analysis. There were nine haplotypes in all samples. The frequency of haplotype CGGGGAGC was significantly higher in cases than in controls $(P=0.0002)$. The frequencies of haplotypes CGGGGAGT, CGGGCAGC, and CGGGGGGC were also significantly higher in cases $(P=0.0001,0.0005$, and 0.0074 , respectively). In contrast, the haplotype CGAAGAGC was more common in the control group than in the case group $(P<0.0001)$. The details are listed in Table 6.

Table 4: ADAM33 genotype frequencies in cases and controls

\begin{tabular}{|c|c|c|c|c|}
\hline & & \multicolumn{2}{|c|}{ Frequency No (\%) } & \multirow[b]{2}{*}{$P$-value } \\
\hline \multicolumn{2}{|c|}{ Genotype } & $\operatorname{CASE}(n=3 \mid 2)$ & CONTROL $(n=319)$ & \\
\hline \multirow[t]{3}{*}{ V4 } & $\mathrm{CC}$ & $200(64.10)$ & $215(67.40)$ & 0.3830 \\
\hline & CG & $93(29.81)$ & $88(27.59)$ & 0.5373 \\
\hline & GG & $19(6.09)$ & $16(5.01)$ & 0.5556 \\
\hline \multirow[t]{3}{*}{$T+1$} & AA & $9(2.88)$ & $7(2.20)$ & 0.5813 \\
\hline & AG & $63(20.20)$ & $64(20.06)$ & 0.9676 \\
\hline & GG & $240(76.92)$ & $248(77.74)$ & 0.8057 \\
\hline \multirow[t]{3}{*}{$\mathrm{T} 2$} & AA & $\mathrm{II}(3.53)$ & $60(18.81)$ & $<0.0001$ \\
\hline & $A G$ & $100(32.05)$ & $139(43.57)$ & 0.0003 \\
\hline & GG & $201(64.42)$ & $120(37.62)$ & $<0.0001$ \\
\hline \multirow[t]{3}{*}{$\mathrm{TI}$} & AA & $83(26.60)$ & $179(56.11)$ & $<0.0001$ \\
\hline & AG & $170(54.49)$ & $122(38.24)$ & $<0.0001$ \\
\hline & GG & $59(18.91)$ & $18(5.65)$ & $<0.0001$ \\
\hline \multirow[t]{3}{*}{ S2 } & $\mathrm{CC}$ & $30(9.62)$ & $23(7.21)$ & 0.2761 \\
\hline & CG & $121(38.78)$ & $105(32.92)$ & 0.1244 \\
\hline & GG & $161(51.60)$ & $191(59.87)$ & 0.0365 \\
\hline \multirow[t]{3}{*}{ SI } & $\mathrm{AA}$ & $|7|(54.81)$ & $200(62.70)$ & 0.0441 \\
\hline & AG & $120(38.46)$ & $99(31.03)$ & 0.0501 \\
\hline & GG & $21(6.73)$ & $20(6.27)$ & 0.8142 \\
\hline \multirow[t]{3}{*}{ Q-I } & $\mathrm{AA}$ & $13(4.17)$ & $40(12.54)$ & 0.0002 \\
\hline & AG & $100(32.05)$ & $130(40.75)$ & 0.0232 \\
\hline & GG & $199(62.38)$ & |49(46.7|) & $<0.0001$ \\
\hline \multirow[t]{3}{*}{$\mathrm{F}+\mathrm{I}$} & $\mathrm{CC}$ & $154(49.36)$ & $159(49.84)$ & 0.9032 \\
\hline & $\mathrm{CT}$ & $\mid 28(4 \mid .03)$ & $138(43.26)$ & 0.5698 \\
\hline & TT & $30(9.61)$ & $22(6.90)$ & 0.2143 \\
\hline
\end{tabular}

\section{Discussion}

The present study is the first demonstration of an association between ADAM33 polymorphisms and COPD in an East Asian population. Using a case-control design, we investigated the relationship between human ADAM33 polymorphisms and COPD in northeast China. Our results showed that the T1, T2, S2, and Q-1 SNPs were significantly associated with COPD. As multiple SNPs may act in combination to increase the risk of COPD, haplotypes were constructed, and their frequencies were compared between the case and control groups. The haplotype data suggests that the CGGGGAGC, CGGGGAGT, CGGGCAGC, and CGGGGGGC haplotypes may be risk factors for COPD. In contrast, the CGAAGAGC haplotype may be a protective factor for the disease.

It is known that lung function decline is a risk factor for the development of COPD and cardiovascular disease [23]. Lee and coworkers demonstrated that ADAM33 protein levels in bronchoalveolar lavage fluid (BALF) are inversely correlated with predicted FEV1 values in patients with asthma [20]. Associations of polymorphisms in ADAM33 with FEV1 decline may therefore constitute a risk for the development of COPD as well. In previous studies, it has been shown that polymorphisms in the ADAM33 gene play a role not only in asthma susceptibility, but in its progression [16]. In a Dutch population, the SNPs S1, S2, and Q-1 were associated with FEV1 decline, and the SNPs S1, S2, F+1, and T2 were associated with the presence of COPD [21]. In another study of European children, SNPs F+1, M+1, T1, and T2 were associated with lower FEV1 [24]. These conflicting results could be due to ethnic differences between the Caucasian populations and the East Asian population in the present study. Another possibility is that there may be differences in the genetic background of COPD in Chinese, Caucasian, and Dutch populations. Therefore, further studies investigating the distributions of the ADAM33 gene variants in other populations is required.

In our study, three SNPs were associated with COPD. The T1 and T2 SNPs are located in the exon 19 (which includes an SH3 domain and a phosphorylation site) of the cytoplasmic tail, which may affect signaling. The SNP Q-1 is located in the intron immediately before exon 16 , 
Table 5: Association of ADAM33 alleles with COPD

\begin{tabular}{|c|c|c|c|c|c|}
\hline \multirow[b]{2}{*}{ SNP } & \multirow[b]{2}{*}{ Allele } & \multicolumn{2}{|c|}{ Minor allele frequency } & \multirow[b]{2}{*}{$P$-value } & \multirow[b]{2}{*}{ Odds ratio $(95 \% \mathrm{Cl})$} \\
\hline & & Case & Control & & \\
\hline V4 & $\mathrm{G}: \mathrm{C}$ & 0.210 & 0.188 & 0.3310 & I.I5 (0.87-I.5I) \\
\hline$T+1$ & $\mathrm{G}: \mathrm{A}$ & 0.130 & 0.122 & 0.6861 & $1.07(0.77-1.49)$ \\
\hline $\mathrm{T} 2$ & $\mathrm{G}: \mathrm{A}$ & 0.196 & 0.406 & $<0.0001$ & $2.81(2.19-3.61)$ \\
\hline TI & $A: G$ & 0.462 & 0.248 & $<0.0001$ & $2.60(2.06-3.30)$ \\
\hline S2 & $\mathrm{G}: \mathrm{C}$ & 0.290 & 0.237 & 0.0313 & $1.31(1.02-1.69)$ \\
\hline SI & $A: G$ & 0.260 & 0.218 & 0.0819 & $1.25(0.97-1.63)$ \\
\hline Q-I & $\mathrm{G}: \mathrm{A}$ & 0.202 & 0.329 & $<0.0001$ & $1.93(1.50-2.50)$ \\
\hline $\mathrm{F}+\mathrm{I}$ & $C: T$ & 0.301 & 0.285 & 0.5321 & $1.08(0.85-1.38)$ \\
\hline
\end{tabular}

which contains an epidermal growth factor (EGF) domain [25]. EGF signaling is important in lung morphogenesis, and mice lacking the EGF receptor (EGFR) demonstrate abnormal branching and poor alveolarization. EGFR signaling regulates matrix metalloproteases, which mediate epithelial-mesenchymal interactions during lung morphogenesis [26]. ADAM33 is closely related to matrix metalloproteases, but may bind EGF directly. A disturbance in the EGF domain will likely affect regulation of ADAM33. Through alterative splicing, exon 16 can be spliced out, giving rise to the $\beta$-variant of ADAM33. This variant was found in 30\% of ADAM33 mRNA transcripts in pulmonary fibroblasts [27]. Because the EGF domain is incomplete, it has been suggested that the $\beta$-variant prevents maturation of ADAM33 and may exert a dominant-negative effect on its protease activity [28]. The intronic Q-1 SNP may therefore influence the splicing of the $\beta$-variant [29] and disturb the maturation of ADAM33. Subsequent effects on protease activity may result in a defect in tissue repair after inflammation-induced damage. This may lead to progressive destruction of alveolar tissue and thereby enhance accelerated decline in lung function.

We have previously shown that polymorphisms in the ADAM33 gene are associated with adult allergic asthma and rhinitis in a Chinese Han population [30]. Interestingly, we now present evidence that polymorphisms in ADAM33 are associated with COPD in a Chinese Han population. In these studies, some common SNPs are associated with all three diseases, suggesting that they contribute to accelerated airway dysfunction in various disease progressions. However, some specific SNPs are only associated with one disease. This phenomenon is consistent with the pathogenetic mechanisms of the three diseases. On one hand, the pathogenetic mechanisms of asthma, allergic rhinitis, and COPD are different from each other, and each disease has its specific diagnosis. On the other hand, there may be some overlapping aspects in their pathogenetic mechanisms. At present, the mechanistic roles of the disease-associated SNPs have yet to be elucidated, especially in the context of the pathophysiology of asthma and COPD. Further research on ADAM33 should clearly involve functional studies to elucidate the roles of ADAM33 SNPs in lung function loss, asthma, and COPD.

\section{Conclusion}

In summary, our results suggest an association between the ADAM33 gene polymorphisms and COPD in the northeastern Chinese Han population.

Table 6: Association of ADAM33 haplotypes with COPD

\begin{tabular}{|c|c|c|c|c|}
\hline \multirow[b]{2}{*}{ Haplotype } & \multirow[b]{2}{*}{ Frequencies } & \multicolumn{2}{|c|}{ Frequencies } & \multirow[b]{2}{*}{$P$ value of $\chi^{2}$-test } \\
\hline & & Case & Control & \\
\hline CGGAGAGC & 0.122 & 0.125 & 0.199 & 0.7353 \\
\hline CGAAGAGC & 0.064 & 0.032 & 0.096 & $<0.0001$ \\
\hline CGGGGAGC & 0.053 & 0.077 & 0.030 & 0.0002 \\
\hline GGGAGAGC & 0.034 & 0.035 & 0.034 & 0.8664 \\
\hline CGGAGAGT & 0.034 & 0.034 & 0.033 & 0.908 \\
\hline CGGGGAGT & 0.03 & 0.049 & 0.012 & 0.0001 \\
\hline CGGGCAGC & 0.027 & 0.043 & 0.011 & 0.0005 \\
\hline CGGGGGGC & 0.027 & 0.039 & 0.015 & 0.0074 \\
\hline CGGACAGC & 0.023 & 0.029 & 0.018 & 0.1904 \\
\hline
\end{tabular}




\section{Competing interests}

The authors declare that they have no competing interests.

\section{Authors' contributions}

XW participated in the molecular study and drafted the manuscript. LL performed the statistical analysis. JX and CJ participated in the statistical analysis and performed haplotype reconstruction. $\mathrm{KH}$ and $\mathrm{XK}$ recruited volunteers. XW participated in the design of the study. FI initiated the study and participated in its design and coordination. All authors contributed to data interpretation and manuscript revisions, and all approved the final manuscript.

\section{Acknowledgements}

This work was funded by the National Natural Science Foundation of China (No.3067 I I46). We also gratefully acknowledge the numerous sample donors for making this work possible.

\section{References}

I. Pauwels RA, Buist AS, Calverley PM, Jenkins CR, Hurd SS: Global strategy for the diagnosis, management, and prevention of chronic obstructive pulmonary disease. NHLBI/WHO Global Initiative for Chronic Obstructive Lung Disease (GOLD) Workshop summary. American journal of respiratory and critical care medicine 200I, I 63(5): I 256-1276.

2. Kim V, Rogers TJ, Criner G]: New concepts in the pathobiology of chronic obstructive pulmonary disease. Proceedings of the American Thoracic Society 2008, 5(4):478-485.

3. DeMeo DL, Silverman EK: Genetics of chronic obstructive pulmonary disease. Seminars in respiratory and critical care medicine 2003, 24(2): $|5|-\mid 60$.

4. Black RA, White JM: ADAMs: focus on the protease domain. Current opinion in cell biology 1998, I O(5):654-659.

5. Primakoff $P$, Myles DG: The ADAM gene family: surface proteins with adhesion and protease activity. Trends Genet 2000 I 6(2):83-87

6. Garlisi CG, Zou J, Devito KE, Tian F, Zhu FX, Liu J, Shah H, Wan Y, Motasim Billah M, Egan RW, Umland SP: Human ADAM33: protein maturation and localization. Biochemical and biophysical research communications 2003, 30 I (I):35-43.

7. Zou J, Zhu F, Liu J, Wang W, Zhang R, Garlisi CG, Liu YH, Wang S, Shah $H$, Wan $Y$, Umland SP: Catalytic activity of human ADAM33. The Journal of biological chemistry 2004, 279(I I):9818-9830.

8. Barnes PJ: Mechanisms in COPD: differences from asthma. Chest 2000, I I7(2 Suppl): IOS- I4S

9. Puxeddu I, Pang YY, Harvey A, Haitchi HM, Nicholas B, Yoshisue $H$ Ribatti D, Clough G, Powell RM, Murphy G, Hanley NA, Wilson DI, Howarth PH, Holgate ST, Davies DE: The soluble form of a disintegrin and metalloprotease 33 promotes angiogenesis: implications for airway remodeling in asthma. The Journal of allergy and clinical immunology 2008, I 2 I(6): |400-|406. I406 el40I1404

10. Hashimoto $M$, Tanaka $H$, Abe S: Quantitative analysis of bronchial wall vascularity in the medium and small airways of patients with asthma and COPD. Chest 2005, I 27(3):965-972.

II. Van Eerdewegh P, Little RD, Dupuis J, Del Mastro RG, Falls K, Simon J, Torrey D, Pandit S, McKenny J, Braunschweiger K, Walsh A, Liu Z, Hayward B, Folz C, Manning SP, Bawa A, Saracino L, Thackston M, Benchekroun Y, Capparell N, Wang M, Adair R, Feng Y, Dubois J, FitzGerald MG, Huang H, Gibson R, Allen KM, Pedan A, Danzig MR, Umland SP, Egan RW, Cuss FM, Rorke S, Clough JB, Holloway JW, Holgate ST, Keith TP: Association of the ADAM33 gene with asthma and bronchial hyperresponsiveness. Nature 2002 , 4 I 8(6896):426-430.
12. Blakey J, Halapi E, Bjornsdottir US, Wheatley A, Kristinsson S, Upmanyu R, Stefansson K, Hakonarson H, Hall IP: Contribution of ADAM33 polymorphisms to the population risk of asthma. Thorax 2005, 60(4):274-276.

13. Howard TD, Postma DS, Jongepier H, Moore WC, Koppelman GH, Zheng SL, Xu J, Bleecker ER, Meyers DA: Association of a disintegrin and metalloprotease 33 (ADAM33) gene with asthma in ethnically diverse populations. The Journal of allergy and clinical immunology 2003, I I 2(4):717-722.

14. Raby BA, Silverman EK, Kwiatkowski DJ, Lange C, Lazarus R, Weiss ST: ADAM33 polymorphisms and phenotype associations in childhood asthma. The Journal of allergy and clinical immunology 2004, I I3(6): I07|- I078.

I5. Werner M, Herbon N, Gohlke H, Altmuller J, Knapp M, Heinrich J, Wjst M: Asthma is associated with single-nucleotide polymorphisms in ADAM33. Clin Exp Allergy 2004, 34(I):26-3I

16. Jongepier H, Boezen HM, Dijkstra A, Howard TD, Vonk JM, Koppelman GH, Zheng SL, Meyers DA, Bleecker ER, Postma DS: Polymorphisms of the ADAM33 gene are associated with accelerated lung function decline in asthma. Clin Exp Allergy 2004, 34(5):757-760.

17. Schedel M, Depner M, Schoen C, Weiland SK, Vogelberg C, Niggemann B, Lau S, Illig T, Klopp N, Wahn U, von Mutius E, Nickel R, Kabesch M: The role of polymorphisms in ADAM33, a disintegrin and metalloprotease 33 , in childhood asthma and lung function in two German populations. Respiratory research 2006 , 7:91.

18. Postma DS, Howard T: ADAM33 gene: confirming a gene without linkage. Clin Exp Allergy 2004, 34(I): I-3.

19. Holgate ST, Davies DE, Powell RM, Holloway JW: ADAM33: a newly identified protease involved in airway remodelling. Pulmonary pharmacology \& therapeutics 2006, I 9(I):3-II.

20. Lee JY, Park SW, Chang HK, Kim HY, Rhim T, Lee JH, Jang AS, Koh ES, Park CS: A disintegrin and metalloproteinase 33 protein in patients with asthma: Relevance to airflow limitation. American journal of respiratory and critical care medicine 2006 , I 73(7):729-735

21. van Diemen CC, Postma DS, Vonk JM, Bruinenberg M, Schouten JP, Boezen HM: A disintegrin and metalloprotease 33 polymorphisms and lung function decline in the general population. American journal of respiratory and critical care medicine 2005 , I 72(3):329-333.

22. Gosman MM, Boezen HM, van Diemen CC, Snoeck-Stroband JB, Lapperre TS, Hiemstra PS, Ten Hacken NH, Stolk J, Postma DS: A disintegrin and metalloprotease 33 and chronic obstructive pulmonary disease pathophysiology. Thorax 2007, 62(3):242-247.

23. Lange $P$, Nyboe J, Jensen G, Schnohr P, Appleyard M: Ventilatory function impairment and risk of cardiovascular death and of fatal or non-fatal myocardial infarction. Eur Respir J 1991, 4(9): $1080-1087$.

24. Simpson A, Maniatis N, Jury F, Cakebread JA, Lowe LA, Holgate ST, Woodcock A, Ollier WE, Collins A, Custovic A, Holloway JW, John SL: Polymorphisms in a disintegrin and metalloprotease 33 (ADAM33) predict impaired early-life lung function. American journal of respiratory and critical care medicine 2005, I 72(I):55-60.

25. Yoshinaka T, Nishii K, Yamada K, Sawada H, Nishiwaki E, Smith K, Yoshino K, Ishiguro H, Higashiyama S: Identification and characterization of novel mouse and human ADAM33s with potential metalloprotease activity. Gene 2002, 282(I-2):227-236.

26. Kheradmand F, Rishi K, Werb Z: Signaling through the EGF receptor controls lung morphogenesis in part by regulating MTI-MMP-mediated activation of gelatinase A/MMP2. Journal of cell science 2002, I I 5(Pt 4):839-848

27. Powell RM, Wicks J, Holloway JW, Holgate ST, Davies DE: The splicing and fate of ADAM33 transcripts in primary human airways fibroblasts. American journal of respiratory cell and molecular biology 2004, 3 I (I): | 3-2 I.

28. Umland SP, Garlisi CG, Shah H, Wan Y, Zou J, Devito KE, Huang WM, Gustafson EL, Ralston R: Human ADAM33 messenger RNA expression profile and post-transcriptional regulation. American journal of respiratory cell and molecular biology 2003, 29(5):57 | -582. 
29. Das M, Harvey I, Chu LL, Sinha M, Pelletier J: Full-length cDNAs: more than just reaching the ends. Physiological genomics 200I, 6(2):57-80.

30. Su D, Zhang X, Sui H, Lu F, jin L, Zhang J: Association of ADAM33 gene polymorphisms with adult allergic asthma and rhinitis in a Chinese Han population. BMC medical genetics 2008, 9:82.

\section{Pre-publication history}

The pre-publication history for this paper can be accessed here:

http://www.biomedcentral.com/1471-2350/10/132/pre

pub

Publish with Biomed Central and every scientist can read your work free of charge

"BioMed Central will be the most significant development for disseminating the results of biomedical research in our lifetime. "

Sir Paul Nurse, Cancer Research UK

Your research papers will be:

- available free of charge to the entire biomedical community

- peer reviewed and published immediately upon acceptance

- cited in PubMed and archived on PubMed Central

- yours - you keep the copyright

Submit your manuscript here:

http://www.biomedcentral.com/info/publishing_adv.asp 